\title{
ethic \\ APEL VERSUS HABERMAS: A TRAJETÓRIA CONTROVERSA DAS DUAS VARIANTES ORIGINAIS DA ÉTICA DO DISCURSO
}

\author{
APEL VERSUS HABERMAS: THE CONTROVERSIAL TRAJECTORY \\ OF THE TWO ORIGINAL VARIANTS OF DISCOURSE ETHICS
}

\author{
ANGELO VITÓRIO CENCI ${ }^{1}$ \\ (UPF/Brasil)
}

\begin{abstract}
RESUMO
A construção da ética do discurso, no que concerne às suas duas variantes originárias, ocorreu sob o signo da controvérsia. Esta deveu-se à forma diferenciada como a esfera da moral do discurso foi sendo tematizada no programa de cada autor e ao modo distinto de eles conceberem o conceito de razão prática. As respostas dadas a essa problemática acerca da esfera própria da moral resultarão em dois programas da ética do discurso que vão se distanciando progressivamente de suas raízes comuns e que irão, ao final, projetar duas concepções de razão prática bastante distintas e, em grande medida, inconciliáveis, de modo a ser impossível reuni-las sob uma mesma rubrica. Assim, em razão da diferença existente no programa inicial de cada autor entre a formulação de uma noção mais estreita de moral - deontológica, como a que defende Habermas - ou mais ampla - deontológico-teleológica, como o propõe Apel - ter-se-á como consequência que, para Habermas, a moral e a razão prática ficarão situadas dentro de uma teoria ou filosofia do discurso e a razão prática não poderá ser compreendida em sentido moral; em Apel, ambas as esferas ficarão situadas dentro da própria ética do discurso, de modo que a moral ocupará a parte A e a esfera da razão prática a parte B - teleológica - e será compreendida em sentido moral.
\end{abstract}

Palavras-chave: Apel; Habermas; Ética do discurso; Razão prática; Moral.

\begin{abstract}
The construction of discourse ethics, with regard to its two original variants, was held under controversy. This was due to the different ways the sphere of moral discourse was addressed in each author's program and to the distinct ways they conceived the concept of practical reason. The answers given to the problem of the very sphere of moral shall bring about two programs of discourse ethics that eventually move away from their common roots and, finally, project two conceptions of practical reason that are quite distinct and, to great extent, incompatible, so that it is impossible to combine them under the same rubric. Thus, due to the differences in each author's initial program concerning the formulation of a stricter notion of moral - deontological, as defended by Habermas - or broader - deontological-teleological, as proposed by Apel - the consequence will be that, for Habermas, moral and practical reason shall be placed within a theory or
\end{abstract}


philosophy of discourse and practical reason cannot be understood in moral sense; in Apel, both spheres shall be placed in discourse ethics itself, so that moral occupies part $A$ and the sphere of practical reason occupies part B - teleological and shall be understood in moral sense.

Keywords: Apel; Habermas; Discourse ethics; Practical reason; Moral.

\section{Introdução}

A ética do discurso desenvolveu-se, em suas duas variantes originais, sob o signo da controvérsia. Ela começou a ser gestada por Jürgen Habermas e Karl-Otto Apel no período que antecedeu a publicação do texto programático deste último, de 1973, intitulado Das Apriori der Kommunicationsgemeinschaft und die Grundlagen der Ethik (APEL, 1999, 358 ss.). A trajetória de quase quatro décadas desse empreendimento intelectual é marcada por contribuições significativas no campo da filosofia moral, tais como o esforço de fundamentação da ética perante o ceticismo moral e a preocupação em mediar um princípio moral, filosoficamente fundamentado, com a ação humana. Esse projeto de teoria moral possui a peculiaridade de ter sido construído a partir de um ponto de partida comum e mediante a interlocução sistemática entre seus dois fundadores. Esses aspectos, assim como o fato de compartilharem ideias e problemas fundamentais no decorrer da trajetória da ética do discurso, favoreceram para que Habermas e Apel fossem identificados com alguma frequência como defensores de um mesmo programa de filosofia moral. Tornou-se, desse modo, um certo lugar comum avaliar os aspectos dissonantes entre eles como sendo apenas diferenças de ênfase.

Todavia, a posição defendida no presente artigo é a de que, apesar das conhecidas afinidades intelectuais e do esforço comum de fundamentação de uma ética do discurso, um exame cuidadoso de seus textos revela divergências mais profundas as quais se referem a problemas que vão muito além da colocação de acentos em diferentes aspectos de um projeto que, à primeira vista, percorreria uma trajetória linear desde seu início. Sustenta-se que as respostas dadas à problemática acerca da esfera própria da moral resultarão em dois programas da ética do discurso que, progressivamente, vão se distanciando de suas raízes comuns e que irão, ao final, projetar duas concepções de razão prática bastante distintas e, em grande medida, inconciliáveis, de modo a tornar-se impossível reuni-las sob uma mesma rubrica. 
A rigor, as diferenças teóricas entre Habermas e Apel podem ser encontradas já em relação ao modo como concebem originariamente seus respectivos projetos de filosofia. Ao remontar-se à pragmática transcendental de Apel e à pragmática universal ou formal de Habermas, é possível notar que ambos se constituem como projetos teóricos que partilham pontos e intenções em comum, mas que, ao mesmo tempo, estruturam-se de modo distinto e com origens em contextos filosóficos diferentes. Por parte de Apel, sua filosofia foi marcada, desde o início, pela questão central acerca de como transformar de modo pós-metafisico o ponto de partida filosófico-transcendental de Kant - a pergunta acerca das condições de possibilidade da validez do conhecimento - para superar a aporia em torno da incognoscibilidade da coisa em si e ajustá-lo ao nível da reflexão acerca de uma teoria crítica das ciências naturais e das ciências sociais.

Dois impulsos teóricos foram decisivos para o programa apeliano de transformação da filosofia transcendental, os quais estão presentes em Transformation der Philosophie, de 1973. O primeiro pode ser identificado pelos programas de investigação levados adiante por meio de uma hermenêutica transcendental da linguagem e de uma antropologia transcendental do conhecimento que começaram a ser desenvolvidos no início da década de 1960, tendo, como principais interlocutores, Heidegger e Wittgenstein. O segundo foi a obra de Peirce, juntamente com o segundo Wittgenstein. O modelo proposto de filosofia e de fundamentação da ética por Apel é moldado, pois, pela transformação da filosofia transcendental de Kant com base num duplo prisma: histórico-hermenêutico e pragmáticosemiótico.

Com efeito, o esforço de Apel, nessa tarefa de fundamentação, é desenvolvido tendo sempre como base seu projeto maior de transformação da filosofia transcendental em diálogo estreito com as grandes correntes da filosofia contemporânea. De Kant, Apel adota o modelo de reflexão transcendental e de uma ética cognitivista, transformando sua filosofia transcendental através de Peirce. De Peirce, adota o conceito de comunidade de comunicação, porém o amplia com Mead da esfera da comunidade dos investigadores para o apriori da comunidade de comunicação real e ideal, ou seja, à humanidade. No segundo Wittgenstein, Apel busca a tese da impossibilidade de uma linguagem privada e confere um caráter renovado - intersubjetivo e público - às evidências de certeza buscadas na tradição. Da tradição hermenêutica, Apel herda, entre outros 
aspectos, a ideia heideggeriana de abertura de sentido, baseada na compreensão do sujeito como um ser imerso na facticidade da existência, o [Dasein]. Por fim, em Habermas, a referência principal para a interlocução é a pragmática universal.

Com seu programa inaugural da ética do discurso, Apel propõe-se, pois, a tarefa de fundamentar racionalmente uma ética do discurso e, para tal, procura invalidar, em disputa com correntes filosóficas contemporâneas, como o racionalismo crítico de Karl Popper e Hans Albert, posições subjetivistas e cientificistas. Os temas presentes em tal programa recebem desdobramentos posteriores também em outros trabalhos e a orientação impressa por essa tarefa de seu programa original guia seus esforços até a metade da década de 1980, quando sua variante da ética do discurso sofre modificações. Apel parte da constatação de que a ética se encontra diante de um paradoxo, sobretudo, se for considerada sua relação com a ciência no contexto da sociedade contemporânea, a qual é marcada fortemente pelas características de uma civilização técnico-científica. Por um lado, apresenta-se a necessidade premente de uma ética universal, principalmente em razão das consequências das ações humanas decorrentes de tal civilização. Por outro, a mesma racionalidade técnicocientífica que provoca tal premência subtrai a legitimidade de uma ética universal, uma vez que monopoliza os atributos de racionalidade e objetividade, de modo que a esfera moral fica relegada ao âmbito privado das decisões subjetivas e irracionais.

Em seu programa inicial, o diagnóstico sobre a situação contemporânea da ética identifica, ao lado dessa postura cientificista, o predomínio da racionalidade estratégica - a qual dificulta a fundamentação de uma solidariedade de caráter interpessoal - e a combinação de existencialismo e positivismo presente nas duas grandes ideologias do século XX: a democracia liberal ocidental e o marxismo ortodoxo oriental (APEL, 1999). O leitmotiv da tarefa assumida por Apel é o de mostrar não apenas a necessidade, mas também a possibilidade e a relevância de uma fundamentação filosófica última e, por conseguinte, também da ética. A seu juízo, isso é possível se a tarefa de fundamentação última não for mais identificada com o modelo desta assumido pela metafísica ontológica tradicional e pela lógica da ciência e se conseguir reconhecer a especificidade de uma racionalidade ética (APEL, 1981).

Essa constatação leva Apel a desenvolver uma espécie de diagnóstico da situação atual da ética e sua principal constatação é que as posições filosóficas aí inscritas não conseguem mais dar conta de fundamentar racionalmente a ética. Neste sentido, sua interlocução intensa com o racionalismo crítico tem, como razão de ser, o fato de este representar a 
posição onde os desdobramentos da problemática da aparente impossibilidade da fundamentação estão caracterizados de modo mais completo e de propor sua substituição por um método falibilista. Outro problema importante que Apel propõe-se a dar conta em seu projeto inicial é o de que, em razão do caráter abstrato do seu princípio moral, a ética do discurso precisa ser formulada também como ética da responsabilidade, a qual deve possibilitar uma mediação entre a racionalidade consensualcomunicativa, própria da esfera do discurso, e a racionalidade estratégica.

Para contornar esse problema, ele articula duas estratégias morais a de conservação ou sobrevivência e a de emancipação - englobando, em sua ética do discurso, já uma teleologia moral. Apel tem em vista aqui, por um lado, evitar o rigorismo moral e, por outro, defender uma ética do discurso como ética da responsabilidade mediante uma fundamentação última. Ocorre que a ética do discurso, pensada do prisma de uma ética da responsabilidade, tem de considerar que os sujeitos morais não podem ignorar as condições reais de ação onde predomina - em sistemas de autoconservação - a racionalidade estratégica. A ação de acordo com o princípio moral ou norma moral fundamental [Grundnorm] não pode ser exigível sem mais em tais circunstâncias. Por essa razão, a tensão existente entre a situação real e a situação ideal de argumentação remete ao dever de se contribuir para a realização das condições para que se estabeleça o princípio moral a longo prazo.

\section{II}

Por parte de Habermas, as investigações filosóficas que orientam seu projeto teórico inicial são pautadas pelo objetivo principal de "desenvolver a ideia de uma teoria da sociedade concebida com intenção prática" (HABERMAS, 1987, 13). ${ }^{2}$ Seus interesses intelectuais orientam-se pela preocupação em tematizar a relação entre teoria e práxis com base num prisma epistemológico. Habermas guia-se pelo propósito de elaborar uma crítica integral ao positivismo a partir do alcance obtido até então pelo problema já colocado por Kant acerca da possibilidade do conhecimento em geral (HABERMAS, 1973). O aprofundamento dessa problemática perpassa a década de 1960. Nas décadas de 1970 e 1980, seu projeto de elaborar uma teoria da sociedade por meio de uma teoria do conhecimento dá lugar a uma teoria da ação comunicativa. Em seu programa de 1983, a ética do discurso é situada a partir desse projeto e de sua aproximação ao modelo das denominadas "ciências reconstrutivas".

Isso não significa, no entanto, que, anteriormente, Habermas não tenha se ocupado com questões de teoria moral. Esboços preliminares do 
que viria a ser a ética do discurso já podem ser encontrados em Arbeit und Interaktion, de 1967, publicado em Technik und Wissenschaft als 'Ideologie' (1968), Erkenntnis und Interesse (1968), sobretudo o epílogo de 1973 dessa obra e, principalmente, em Legitimationsprobleme im Spätkapitalismus (1973). Na última parte desse livro, Habermas já se ocupa explicitamente de questões de teoria moral, orientando-se ali - conforme ele próprio observará depois - por um "modelo de 'interesses reprimidos suscetíveis de universalização'" (HABERMAS, 1990, 115). Trata-se, na verdade, do primeiro esboço do programa de uma moral universalista de princípios que seriam desenvolvidos a partir do início da década de 1980, em Moralbewusstsein und Kommunikatives Handeln (1983).

Com a apresentação desse programa, o projeto de uma ética do discurso, desenvolvido, inicialmente, com base numa perspectiva geral comum e orientado até então de modo mais sistemático pelo programa de Apel, também sofre modificações significativas. ${ }^{3}$ O programa de Habermas toma como base uma teoria da ação comunicativa e uma concepção pragmático-formal do significado (HABERMAS, 1995). Não se estrutura, pois, mediante o projeto de uma transformação da filosofia transcendental de Kant e uma pragmática transcendental, como o fizera Apel. Seu programa é ancorado em uma concepção de filosofia que se aproxima das ciências reconstrutivas, incorpora uma perspectiva falibilista e um modelo transcendental fraco de fundamentação, ao invés de uma fundamentação última como almejado por Apel. Isso Ihe possibilita reformular o argumento pragmático-transcendental de Apel e, diferentemente do que ocorre no programa deste, os pressupostos da argumentação não possuem um teor normativo-moral, mas apenas normativo. Por conseguinte, o conceito habermasiano de discurso não é impregnado de modo moral-normativo, como também não o seria posteriormente, na década de 1990, em Faktizität und Geltung.

Também o princípio moral $(U)$ assume uma feição distinta da norma moral fundamental apeliana. Em seu caráter formal, $(U)$ constitui-se numa regra de argumentação, sem vincular um dever moral em relação ao agir, deixando os conteúdos a encargo dos discursos reais. Porém, assim como Apel, Habermas também se preocupa em fugir do risco de incorrer no rigorismo moral, de modo que (U) já traz consigo o princípio de uma ética da responsabilidade própria para a avaliação das consequências e dos efeitos colaterais oriundos das ações humanas coletivas. Esse problema permanece, então, circunscrito ao âmbito de uma moral deontológica, sem agregar-Ihe uma dimensão teleológica como o fizera Apel. Os programas de Habermas e Apel têm, claramente, como ponto comum, a filiação à perspectiva kantiana de uma moral deontológica, mas renovada em termos 
discursivos. No entanto, o modo de conceber esse deontologismo é diferenciado desde o início entre os dois fundadores da ética do discurso, uma vez que Apel, de modo distinto de Habermas, o assumirá com certas reservas e acrescentará à ética do discurso uma dimensão teleológica, procurando imprimir-lhe a feição de uma estratégia moral e evitar, entretanto, um telos substancial da vida boa.

A forma como Habermas elabora agora seu programa da ética do discurso traz consigo modificações significativas em relação ao modo como Apel o apresentara até então. No centro das modificações introduzidas por Habermas com seu programa de fundamentação estão as especificações feitas por ele em torno de sua noção da moral do discurso, considerada segundo "limites estreitos" e sob "enérgicas abstrações", uma vez que se configura como moral especificamente deontológica. Com essa especificação, Habermas concede, já na formulação de seu programa inicial, um âmbito mais estreito que Apel à esfera da moral do discurso e assenta a base para o desdobramento das divergências programáticas que se seguiriam entre ele e Apel a partir de então no interior da ética discursiva.

As diferenças entre os dois projetos de teoria moral revelam-se, pois, importantes, já nos textos dos anos 1980. Na versão habermasiana inicial da ética do discurso, possuem destaque aspectos fundamentais presentes em sua teoria da ação comunicativa, uma vez que desta são extraídos os pressupostos de sua ética do discurso e é apresentado o modo como esta é fundamentada. Ao explicitar seu modelo de fundamentação Habermas, ao mesmo tempo, circunscreve sua moral como estritamente deontológica e, pois, configura-a de acordo com uma noção mais estreita que aquela proposta por Apel em seu programa original. Diferentemente da variante apeliana da ética do discurso, que é formulada a partir do contexto mais amplo do projeto de uma crítica e transformação da filosofia transcendental, a habermasiana é moldada a partir de sua teoria da ação comunicativa e em diálogo com o programa de fundamentação já elaborado por Apel. Habermas entende que a ética do discurso deve tomar como referência os pressupostos da comunicação que todo sujeito tem de fazer intuitivamente toda vez que pretender participar seriamente de uma argumentação. Os problemas com que a ética ocupa-se estão alojados na esfera da ação comunicativa e, para serem explicitados, terão de tomar, como base, uma investigação pragmático-formal do agir comunicativo.

Em sua teoria da ação comunicativa, Habermas começa por distinguir a ação comunicativa dos demais tipos de ação, como a instrumental e a estratégica, o que lhe permite diferenciar duas atitudes básicas dos sujeitos na interação: a voltada ao entendimento e a orientada ao êxito. Desenvolve, então, a tese de que o uso originário da linguagem é aquele 
voltado ao entendimento, do qual os demais usos - como o estratégico são parasitários. A tese do parasitismo confere primazia à ação comunicativa sobre o agir estratégico. Esse passo é decisivo para a estratégia de Habermas, pois, se a ação social fosse ditada por ordens instrumentais, não seria possível fundamentar a ética. A sua pretensão é explicitar, mediante a teoria da ação comunicativa e com base numa reapropriação da teoria dos atos de fala, os mecanismos que permitem coordenar intersubjetivamente a ação. Seu foco volta-se para a análise das estruturas gerais que estão na base dos processos de entendimento, já que o entendimento funciona como mecanismo coordenador da ação e visa à obtenção de um acordo acerca da validez de um ato de fala ou de uma manifestação entre os participantes de uma interação. Trata-se de um mecanismo que permite o reconhecimento intersubjetivo de pretensões de validez criticáveis por meio das quais os participantes da interação apresentam-se uns diante dos outros. Habermas trata, então, das condições que um acordo comunicativo precisa satisfazer para cumprir as funções de coordenação da ação. Ele procura mostrar que o êxito de um ato de fala depende do compromisso assumido pelo falante em relação ao ouvinte, de maneira que este possa confiar na oferta feita por aquele através das pretensões de validez levantadas. Ademais, indica como esse compromisso vincula obrigações e gera efeitos importantes para a sequência da interação (HABERMAS, 1995).

A estratégia de Habermas para chegar à apresentação de seu programa de fundamentação da ética do discurso pressupõe, portanto, alguns passos prévios. O primeiro é o de esclarecer, mediante a ação orientada ao entendimento - via a pragmática formal -, o que significa os atores orientarem-se por pretensões de validez (teoria da ação). A partir daí, é colocado o problema acerca do que significa o resgate ou a resolução discursiva de pretensões de validez normativas. Esse problema requer, por sua vez, uma investigação dos "pressupostos comunicativos da fala argumentativa $[\ldots]$ e a análise das regras universais de procedimento para as argumentações (lógica do discurso)" (HABERMAS, 1984, 444). As questões básicas da ética, tais como a do sentido das proposições normativas e a da fundamentação da ética, aparecem somente no âmbito de uma lógica do discurso prático. Ocorre que, para Habermas, a lógica de tal discurso é considerada imprescindível para a fundamentação da ética, porque, nela, as normas do discurso racional são consideradas como condições pragmático-universais de toda e qualquer fundamentação de normas.

O processo para chegar à fundamentação do princípio moral habermasiano é constituído, então, por três passos: no primeiro, como 
forma também de sustentar o cognitivismo moral, Habermas propõe-se explicitar a especificidade de uma pretensão de validez própria à esfera normativa; no segundo, introduz (U) como princípio-ponte com a finalidade de permitir o trânsito do particular para o universal e possibilitar, enquanto regra de argumentação moral, o consenso na esfera do discurso prático; no terceiro, leva adiante a própria fundamentação do princípio $(U)$, o qual é derivado dos pressupostos da argumentação (HABERMAS, 1983). Este último constitui-se no passo mais importante e é em torno dele que se configuram mais diretamente as divergências de Habermas com Apel, sobretudo, ao defender um modelo de fundamentação mais fraco que o proposto pela pragmática transcendental e ao operar uma transformação do argumento pragmático-transcendental apeliano.

O programa habermasiano de fundamentação da ética do discurso inaugura uma variante própria dentro do projeto de teoria moral mais amplo partilhado, inicialmente, com Apel. Ao desenvolver seu modelo de fundamentação, Habermas apresenta a moral como estritamente deontológica, dando-lhe uma configuração mais estreita que aquela proposta por Apel em seu programa original. Essa diferença será de grande importância para caracterizar as divergências programáticas que vão se configurando e se tornando mais profundas na ética do discurso entre a variante de cada um dos dois autores.

\section{III}

Os trabalhos elaborados por Karl-Otto Apel, a partir da segunda metade da década de 1980, são marcados não apenas por novos desdobramentos que complementam os esforços já empreendidos em conjunto com Habermas na formulação de uma ética do discurso, mas também por divergências importantes em relação ao programa deste último. ${ }^{4}$ Elas incidem, principalmente, sobre o modo como Habermas configurou a esfera própria da moral discursiva. Apel não considera suficiente, por exemplo, a posição habermasiana de que (U) já contemple o princípio de uma ética da responsabilidade. A seu juízo, esse problema demanda um princípio de complementação (C) e uma parte B para a ética. A arquitetônica de Apel apresenta mudanças significativas também em relação ao formato de ambos os programas originais. É o caso da introdução das normas morais fundamentais de justiça, solidariedade e corresponsabilidade, da estruturação clara de uma dimensão teleológica guiada por um princípio de complementação como parte da arquitetônica da ética do discurso e do desenvolvimento do problema da aplicação vinculado a ela. Apel, ao estruturar agora seu programa em duas partes, 
formata arquitetonicamente os contornos do seu conceito da moral discursiva, pretendendo atribuir-lhe uma dimensão mais ampla do que a de Habermas.

O que marca esse momento da controvérsia é o fato de a ética do discurso apeliana assumir, claramente, em seu programa, um caráter deontológico-teleológico. Ocorre que, em razão de a noção de moral do discurso habermasiana ser considerada a partir de "limites estreitos" e sob "enérgicas abstrações", uma vez que se configura como moral especificamente deontológica, Apel aceita com reservas o predicado deontológico para a ética do discurso. Esta incorporará agora, arquitetonicamente, um caráter teleológico e seu programa passa a ser marcado, definitivamente, como modelo deontológico-teleológico, ou seja, como uma ética de dois níveis. De acordo com o primeiro nível, o a priori do discurso apeliano possui teor normativo-moral visto que os pressupostos irretrocedíveis da argumentação assumem valor de normas morais fundamentais, a saber, justiça, solidariedade e corresponsabilidade. No segundo nível, seu programa incorpora uma parte $B$, orientada por um princípio de complementação estratégico-moral (APEL, 1988, 1992).

Essa posição distingue-se da de Habermas, para o qual a moral do discurso assume um caráter especificamente deontológico. Na formulação da arquitetônica apeliana das partes A e B, são mantidos aspectos fundamentais já presentes no programa inicial, como a defesa de uma fundamentação última e a dialética entre comunidade real e comunidade ideal de comunicação. Todavia, ao mesmo tempo, são explicitados novos aspectos em relação a ele. Na nova arquitetônica, a tarefa de fundamentação da ética é dividida em duas partes: o princípio (U) terá lugar na parte $A$ e as esferas, como o direito e a ética política, ficarão situadas na parte $B$.

Se no seu programa original Apel já havia procurado garantir uma dimensão teleológica à ética do discurso, sobretudo para dar conta da mediação entre ação comunicativa e ação estratégica, agora tal dimensão será aprofundada. A mediação entre racionalidade comunicativa e racionalidade estratégica é atribuída ao princípio de complementação (C) e é-Ihe reservada a parte $B$ da fundamentação. A parte B da ética aprofunda a dimensão de ética da responsabilidade da ética do discurso e postula uma estratégia moral que visa à superação, a longo prazo, da necessidade do agir estratégico. A parte $A$ da ética será, ao mesmo tempo, imprescindível e insuficiente. Já anteriormente, em Transformation der Philosophie (Bd. II), Apel havia observado que a diferença entre a comunidade real e a comunidade ideal de comunicação determinava um duplo princípio regulativo para uma ética da responsabilidade. Porém, isso não é feito, 
como agora, mediante a distinção das partes A e B e os desdobramentos decorrentes dela.

A seu juízo, esse duplo princípio deve contribuir para assegurar a sobrevivência do gênero humano, enquanto comunidade real, e realizar a comunidade ideal na primeira. A exigência da realização da comunidade ideal na real constitui um princípio de emancipação, depois desenvolvido e denominado, para evitar mal-entendidos - por exemplo, um utopismo substantivo -, de "princípio de complementação" (princípio C). Com ele, Apel defende que a reflexão pragmático-transcendental sobre os pressupostos da argumentação descobre, além do princípio de universalização da ética como tal, um princípio estratégico-moral de complementação, que permite a fundamentação de uma ética da responsabilidade (parte $B$ da ética).

Vinculado à nova arquitetônica, está também o problema da aplicação. A juízo de Apel, a ética do discurso tem de levar em conta o fato de que a ação humana ocorre num mundo onde predomina a ação estratégica, típica dos sistemas de autoafirmação, de modo que as condições históricas para a aplicação de seu princípio não podem ser simplesmente pressupostas. Por essa razão, o problema da aplicação tem de se converter no problema acerca da realização das condições de aplicação da ética do discurso. Essa forma de colocar o problema da responsabilidade explicita uma diferença importante em relação a Habermas. Para este, a ética do discurso, da maneira como apresenta o princípio de universalização (U), já se constitui como ética da responsabilidade. Para Apel, a aplicação do princípio do discurso requer mais um nível em termos de responsabilidade e, desse aspecto, decorre uma maior complexidade para sua ética, ou seja, além de postular um princípio complementar, introduz uma parte B. A ética habermasiana, em contrapartida, apresenta-se como exclusivamente deontológica. Por conseguinte, os conteúdos morais são levados em conta somente no nível do procedimento dos discursos prático-reais para a reconstrução, fundamentação e aplicação destes. Em Apel, diferentemente, o a priori do discurso já assume um caráter normativo-moral. Essas linhas gerais configuradoras da nova arquitetônica da variante apeliana da ética do discurso marcam definitivamente a moldura que esta assumirá daí para a frente.

\section{IV}

No começo da década de 1990, sobretudo em Faktizität und Geltung, Habermas desenvolve alterações em sua teoria do discurso que repercutem 
de forma marcante sobre seu programa da ética do discurso e que acentuarão suas divergências com a variante apeliana desta. Ele introduz um princípio do discurso neutro em relação à moral e ao direito e passa a falar em "teoria" ou "filosofia do discurso" ao invés de "ética do discurso". Nesta teoria ou filosofia do discurso, a razão prática é dividida em diferentes esferas: as questões éticas referem-se ao autoentendimento de identidades, biografias e ideais de vida; as questões morais referem-se à solução justa ou imparcial de problemas do ponto de vista da universalização de interesses de forma racional, e as questões pragmáticas, à utilidade da ação no aspecto da escolha racional de meios e fins (HABERMAS, 1991, 109 ss.). Por essa razão, a teoria discursiva da moral reconstruirá somente um âmbito parcial ou específico do amplo campo da razão prática, não possuindo primazia dentro desta. A arquitetônica apeliana incorreria, a juízo de Habermas, no erro de sustentar essa pretensão.

Habermas continua a conceber a moral do discurso como estritamente deontológica, limitada a esclarecer e fundamentar o ponto de vista moral, e entende, neste sentido, que tal fundamentação deva se dar com base num modelo transcendental fraco. Refuta, portanto, tanto uma fundamentação última quanto um hibridismo dentro da ética, como faz Apel, quando este vincula ao deontologismo discursivo uma dimensão teleológica mediante um princípio de complementação (C). Ao mesmo tempo, Habermas desenvolve críticas a aspectos centrais da arquitetônica apeliana das partes $A$ e $B$ da ética. ${ }^{5}$ Para Habermas, ao conteúdo lógicocognitivo da ética do discurso não deve ser acrescentada uma parte $\mathrm{B}$. Tal conteúdo deve, de modo distinto, ser complementado mediante uma teoria discursiva do direito, na qual o conceito de discurso ainda não abarca em si pressuposições de caráter moral.

Outro aspecto importante da diferenciação discursiva habermasiana será a ideia de que, assim como a razão prático-moral não representa toda a razão prática, também os discursos morais não representam o conjunto da esfera do discurso. Habermas (1998) distingue diferentes tipos de discursos: os pragmáticos, os ético-existenciais, os morais, os de aplicação e as negociações. A razão prática é diferenciada mediante tais discursos e os discursos morais não detêm mais o monopólio dentro dela. Esse conceito de razão prática traz um aspecto totalmente novo em relação ao programa original da vertente habermasiana da ética do discurso, pois a teoria discursiva do direito é colocada em condições de igualdade ao lado da teoria discursiva da moral. O conceito de discurso relacionado ao direito complementa o discurso prático-moral em função dos contextos do agir concreto, de caráter legal, presentes em Estados democráticos de direito. 
Ele possibilita discutir as questões práticas do agir responsável mediante conceitos de comportamento com referência à lei.

Além disso, Habermas elabora uma teoria discursiva do direito que, junto com a teoria discursiva da moral, culmina numa teoria política da democracia, completando, assim, a esfera da razão prática discursiva. 0 conceito clássico de razão prática passa, no entanto, por uma profunda reformulação, operada à luz da teoria do discurso, o que trará modificações em sua teoria moral. Na opinião de Habermas (1998, 663, [Posfácio]), com a guinada linguística, o conceito moderno de razão prática, amparado na filosofia do sujeito, desintegrou-se, o que o leva a sugerir que a moral deontológica deva ser interpretada em termos da teoria do discurso. A seu juízo, a inserção do princípio de complementação e de uma parte B para a ética na vertente apeliana apontaria para a tentativa de uma autossuperação reflexiva da ética do discurso. A introdução do princípio complementar na ética do discurso por Apel indicaria, desse modo, o rompimento dos limites de uma moral formulada em termos estritamente deontológicos.

Para Habermas, essa tentativa de autossuperação seria consequência do hibridismo da versão apeliana da moral do discurso, que agrega em seu interior uma perspectiva teleológica. Isso poderia ser evitado se a moral do discurso, deontológica e pós-convencional, se limitasse à tarefa de esclarecer e fundamentar o ponto de vista moral. Ao firmar essa posição, Habermas delimita o espaço da moral, ao mesmo tempo em que amplia o âmbito da razão prática para a esfera da ética, da pragmática e do direito. Ele propõe-se, assim, encetar um caminho diferente do percurso traçado pela filosofia moderna e por Apel. A razão prática não será mais lida com base numa chave moral como o faz Apel. Uma das principais consequências dessa divergência é o redimensionamento da forma de articular o vínculo entre moral e razão prática, rompendo com o primado apeliano da moral no interior da razão prática e defendendo a substituição deste último conceito pelo de razão comunicativa.

Em suma, no começo da década de 1990, Habermas recusa o modelo arquitetônico deontológico-teleológico das partes A e B da ética proposto por Apel e opera transformações importantes em relação ao seu próprio programa de 1983. Além de divergir das novas especificações conferidas por Apel à ética do discurso, passa a situar a moral do discurso segundo a perspectiva de uma teoria ou filosofia do discurso, que é estruturada mediante um princípio do discurso neutro em relação à moral e ao direito e por meio de uma diferenciação dos discursos da razão prática. Agora, a moral do discurso é situada como uma das regiões da teoria do discurso e colocada como co-originária e complementar ao direito. Sua teoria do 
discurso modifica-se, abrindo espaço para uma teoria discursiva do direito, e o conceito de razão prática é reformulado nos moldes de um conceito de razão comunicativa, o qual não é prescritivo, ou seja, não é abarcado pela esfera moral. Da sua perspectiva, a razão prática, por não poder ser prescritiva, deve ser mais ampla que a esfera da moral.

Apresenta, então, seu programa acerca da diferenciação dos discursos da razão prática e de sua diferenciação entre moral e direito, bem como uma abordagem dos déficits da moral em relação ao direito, avançando em relação ao problema da aplicação da moral do discurso. Este último é tematizado por Habermas com base no conceito de discurso de aplicação e de um princípio de adequação, não sendo hospedado numa parte B da ética, de caráter teleológico, como o fizera Apel. A moral discursiva é, pois, situada por Habermas dentro do quadro de uma teoria do discurso, a qual diferencia tipos de discursos dentro da esfera da razão prática, e, neste sentido, a moral será claramente distinguida da razão prática, sem possuir primazia dentro desta (HABERMAS, 1998).

\section{$\mathbf{V}$}

A juízo de Apel, em Faktizität und Geltung (1992) o projeto comum entre ele e Habermas de elaboração de uma ética do discurso parece dissolver-se definitivamente, o que se deveria, sobretudo, a duas razões. A primeira é que, na nova arquitetônica de Habermas, o termo "ética" é reservado para designar um projeto específico, o da autorrealização individual ou coletiva. Não bastasse - e essa é a segunda razão -, o tema da filosofia moral é distinguido do princípio do discurso de modo problemático, pois este é apresentado pela primeira vez como neutro em relação à moral. Por se referir a normas de ação em geral e explicitar apenas o ponto de vista a partir do qual as normas de ação podem ser fundamentadas imparcialmente, o princípio do discurso levanta a suspeita, para Apel, de uma dissolução da tarefa de fundamentação da ética do discurso. No entanto, Habermas pretende que ele, ao mesmo tempo enquanto princípio dotado de conteúdo normativo -, exerça ainda a função de fundamento para a diferenciação dos discursos práticos, como os da moral, da ética e do direito.

A juízo de Apel, com essa posição Habermas não estaria contestando apenas a fundamentação pragmático-transcendental última da ética, mas, de modo geral, a implicação imediata do princípio moral no princípio do discurso. Como consequência, a ética do discurso deixa de ser a disciplina de base da filosofia prática. A exigência de retitude moral não pertence mais às pressuposições necessárias da argumentação enquanto tal. Desse modo, 
Habermas abandonaria o próprio conceito original de uma pragmática universal e perder-se-ia, sobretudo, a possibilidade de se levar adiante uma fundamentação pragmático-transcendental da ética, mediante uma reflexão acerca das pressuposições irretrocedíveis da argumentação. Se, em formulações anteriores, como a de 1983, a ética do discurso habermasiana aparecia como base da filosofia prática, agora é substituída por uma filosofia ou teoria do discurso moralmente neutra.

Com essas novas formulações referentes à teoria do discurso de Habermas - sobretudo pela diferenciação dos discursos da razão prática e a introdução de um princípio do discurso neutro em relação à moral e ao direito -, as divergências entre os dois programas da ética do discurso tornam-se ainda mais complexas do ponto de vista programático. Em contrapartida a Habermas, Apel, especialmente em Auflösung der Diskursethik? (1998), aprofunda sua posição já apresentada anteriormente através da arquitetônica das partes $A$ e $B$, imprimindo, enfaticamente, um teor moral ao princípio do discurso - agora denominado de princípio primordial do discurso -, de modo que a esfera da razão prática é hospedada na parte $B$ da ética e passa a ser definida ainda mais claramente em sentido moral. A resposta de Apel às mudanças introduzidas por Habermas é uma radicalização, em chave pragmático-transcendental, de sua posição contrastando à estratégia de "diferenciação dos discursos da razão prática" de Habermas uma "ampliação pragmático-transcendental da ética do discurso" (APEL, 1998).

A estratégia de Apel é, então, confrontar o seu princípio primordial do discurso, de teor moral, com o princípio do discurso neutro em relação à moral e ao direito de Habermas. Isso leva Apel a retomar também o problema da obrigação moral e a ampliar seu conceito de ética da responsabilidade, bem como a tratar do problema da justificação ética da coerção do Estado de direito, diferenciando-se uma vez mais do programa habermasiano da ética do discurso. Apel recebe, pois, as modificações apresentadas por Habermas, em Erläuterungen zur Diskursethik (1991) e, principalmente, em Faktizität und Geltung (1992), de modo crítico, elaborando, com base nelas, uma nova tentativa de pensar com Habermas contra Habermas. A seu ver, porém, essa tentativa é mais complexa e possui um alcance muito mais amplo que as anteriores, uma vez que o que está em questão agora é a temática central da diferenciação dos discursos da razão prática. Sua pretensão é delinear os pontos de partida para uma crítica e revisão da posição habermasiana à luz da pragmática transcendental. Embora sejam vários os pontos de discordância para com Habermas, os principais problemas identificados são reunidos em torno de dois aspectos. O primeiro está em que, nas Tanner Lectures, de 1986, 
Habermas sustentava ainda o primado da filosofia moral sobre a filosofia do direito (HABERMAS, 1998, 541-599). Em Faktizität und Geltung, de 1992, no entanto, operou-se uma modificação importante na estrutura de sua filosofia prática ao colocar, no topo desta, um princípio do discurso neutro em relação à moral e ao direito, não mais, como antes, o princípio do discurso enquanto base do conjunto da filosofia prática. De ora em diante, o princípio moral e o princípio da democracia devem proceder de maneira co-originária ao princípio do discurso.

O segundo ponto está em que o princípio do direito é apresentado como idêntico ao princípio da democracia. O princípio da democracia é constituído na linguagem do direito, assumindo a forma positiva do igual direito de participação política para todos os cidadãos. Essa equivalência decorre da pressuposição habermasiana - advinda da teoria do discurso de que os discursos entre cidadãos livres e iguais em direitos reúne condições de assegurar que os legisladores estejam ao mesmo tempo submetidos às leis (HABERMAS, 1998, 112 ss.; APEL, 2001, 68). Isso significa que os direitos dos cidadãos devem ser garantidos por esses próprios legisladores enquanto autônomos. O princípio do discurso concebido agora de forma bifurcada e a diferenciação dos discursos gerarão modificações em relação a aspectos importantes da configuração da variante da ética do discurso, tal como elaborada por Habermas anteriormente, de modo que o que está em jogo dessa vez é algo mais complexo que nas controvérsias anteriores. Trata-se, a juízo de Apel (1998, 733), da necessidade de "reabilitação" do programa da ética do discurso dada a suspeita de sua "dissolução" por Habermas.

Neste sentido, Apel vai agora opor o seu princípio primordial do discurso ao princípio do discurso moralmente neutro de Habermas. Para Apel, o princípio moral está contido no próprio princípio primordial do discurso em toda sua extensão, abrangendo o princípio $(U)$ como princípio da moral ideal do discurso e o princípio (C) como princípio de uma ética da responsabilidade referida à história. O fato de o princípio primordial do discurso abranger as normas morais fundamentais e, pois, ser mais amplo que $(U)$ - por este cobrir somente a moral ideal do discurso - permitiu, ao invés de formular uma estratégia de diferenciação dos discursos, a partir de um princípio do discurso moralmente neutro, postular uma estratégia de ampliação da própria ética do discurso.

Essa controvérsia é levada adiante por Apel com base num exame detalhado e crítico da nova arquitetônica habermasiana e pela simultânea retomada e aprofundamento, em chave pragmático-transcendental, de aspectos fundamentais de sua própria variante ético-discursiva. Agora, Apel não apenas confronta o princípio do discurso de Habermas e sua 
arquitetônica da ramificação dos discursos, como pretende também aprofundar aspectos centrais de sua arquitetônica das partes A e B, sobretudo ao firmar o conceito de um princípio primordial do discurso. Essa posição possibilita-Ihe demarcar e aprofundar uma compreensão mais ampla que a habermasiana no que diz respeito ao vínculo entre moral e razão prática, uma vez que esta última é abrangida pela própria ética do discurso.

\section{Conclusão}

No percurso desenvolvido, procurou-se apresentar a trajetória das duas variantes originais da ética do discurso como marcadas pela controvérsia. Em tal exposição, salientou-se o papel exercido pelo projeto de filosofia de Habermas e pelo programa de sua ética do discurso - este último apresentado em 1983 - como instauradores das diferenças programáticas entre os dois filósofos. Para dar conta da tarefa de fundamentação e, pois, de delimitação de sua concepção de moral, ele tomou, como ponto de partida, uma teoria da ação comunicativa e introduziu um conceito de moral de caráter especificamente deontológico. Com essa formulação, conferiu uma base mais estreita à esfera da moral que aquela sugerida no programa inicial de Apel. A partir desse momento, tais programas passaram por reformulações internas e explicitaram divergências significativas entre si. Procurou-se mostrar, então, como essas divergências foram ganhando corpo na sequência da trajetória da ética do discurso.

Neste sentido, se, inicialmente, Apel já havia proposto a introdução de uma dimensão teleológica em sua concepção da ética do discurso, com a apresentação da arquitetônica das partes A e B, esta assumiu, definitivamente, uma feição deontológico-teleológica e a esfera da moral configurou-se como mais ampla que em Habermas. Procurou-se mostrar como a ética do discurso apeliana visou englobar na parte B o amplo campo da razão prática, como as questões da ética política e do direito e o problema da aplicação. Ao ser talhada em definitivo como uma ética deontológico-teleológica, a ética apeliana continuou dentro do objetivo fundamental, partilhado com Habermas, de ir além do deontologismo abstrato de Kant. Porém, o modo como foi levado adiante esse intento o diferenciou e fez divergir de Habermas. Ao ser articulada em dois níveis e ao abranger a esfera da razão prática dentro dela, a ética do discurso apeliana passou a caracterizar-se como uma teoria moral mais complexa e mais ampla que a habermasiana. 
Viu-se que, com as novas determinações assumidas em relação à teoria do discurso, particularmente, com a diferenciação dos discursos da razão prática, Habermas distanciou-se ainda mais do programa original de Apel e da arquitetônica das partes A e B. A teoria discursiva da moral formulada deontologicamente foi colocada ao lado da teoria discursiva do direito, de maneira que esta culminou numa teoria política da democracia, completando, assim, a esfera da razão prática discursiva. Com essas especificações, a posição de Habermas firmou ainda mais claramente a delimitação deontológica da esfera da moral do discurso, ao mesmo tempo em que procurou fazer com que sua concepção de razão prática fosse claramente distinguida em relação àquela.

Ao propor a substituição do conceito de razão prática pelo de razão comunicativa, Habermas indicou que esta não pode mais ser entendida em sentido prático-moral, situando a ética do discurso dentro do novo quadro teórico da teoria do discurso. Em razão disso, a teoria discursiva da moral assumiu como função reconstruir somente um âmbito parcial do campo maior da razão prática, não possuindo primazia dentro desta. Com a reformulação do conceito de razão prática, operada à luz da teoria do discurso, observou-se que Habermas, ao mesmo tempo, ampliou o âmbito da razão prática para a esfera da ética, da pragmática, da política e do direito e manteve o conceito de moral do discurso sob limites estreitos, restrito à função de esclarecer e fundamentar o ponto de vista moral. Sua posição, claramente, foi a de evitar extrapolar os limites deontológicos da moral discursiva e, portanto, de não aceitação de uma dimensão teleológica para a ética do discurso. Desse modo, o papel atribuído à esfera da moral relativamente ao da razão prática foi significativamente mais restrito que aquele proposto por Apel.

A postura de Habermas, com a sua diferenciação dos discursos da razão prática, levou Apel a radicalizar ainda mais sua posição na perspectiva pragmático-transcendental, passando a denominar o princípio do discurso como princípio primordial do discurso, defendendo que este tem de ser mais abrangente que o princípio (U), o que implica acentuar a distinção das partes A e B da ética. Apel, de modo diferente de Habermas, estendeu seu conceito de moral ou de ética do discurso de modo a abarcar todo o campo da razão prática como parte $B$ da ética. Neste sentido, procurou-se mostrar que a estratégia de contrapor à proposta de diferenciação dos discursos uma arquitetônica da ampliação visava justamente ampliar o alcance da ética do discurso em razão de abranger as dimensões da razão prática, tais como o direito e a ética política dentro dela. Desse modo, foi possível observar um esforço gradativo por parte de Apel em configurar à ética a primazia em relação à esfera da razão prática, de modo que a cada embate 
com Habermas sua posição de que a moral abrange as demais regiões da razão prática vai ficando mais radicalizada. A trajetória da ética do discurso, avaliada internamente aqui, mediante seus dois expoentes principais, revelou o delineamento progressivo de dois programas teóricos que foram se constituindo um por referência ao outro e assumindo feições cada vez mais distintas.

Pode observar-se, ao final, duas formas distintas de conceber a esfera própria da moral na ética do discurso - uma elaborada com caráter especificamente deontológico; outra de cunho deontológico-teleológico - e a projeção de duas concepções de razão prática bastante diferentes - uma não prescritiva, outra entendida em sentido prático-moral. Por conseguinte, a forma de entender a relação da esfera da moral com a razão prática configurou-se também de modo diferenciado em cada programa. Assim, em razão da diferença existente no programa inicial de cada autor entre a formulação de uma noção mais estreita de moral - deontológica, como a defende Habermas - ou mais ampla - deontológico-teleológica, como o propõe Apel - ter-se-á como consequência que, para Habermas, a moral e a razão prática ficarão situadas dentro de uma teoria ou filosofia do discurso e a razão prática não poderá ser compreendida em sentido moral. Para Apel, por outro lado, ambas as esferas ficarão situadas dentro da própria ética do discurso, de modo que a moral ocupará a parte A e a esfera da razão prática, a parte $B$ - teleológica - e será compreendida em sentido moral. Uma leitura interna atenta da trajetória das duas variantes originais da ética do discurso possibilita, pois, interpretá-la como caracterizada pelo signo da controvérsia. 


\section{Notas}

1 Professor da Universidade de Passo Fundo (UPF/RS); E-mail: angelo@upf.br; Orcid: https://orcid.org/0000-0003-0541-2197

2 Todas as traduções são da responsabilidade do autor.

3 Isso ocorre, sobretudo, mediante: Diskursethik - Notizen zu einem Begründungsprogramm. In: HABERMAS, J. Moralbewusstsein und Kommunikatives Handeln. Frankfurt am Main: Suhrkamp, 1983. São significativos, desse período, também os trabalhos: Die Philosophie als Platzhalter und Interpret e Moralbewusstsein und kommunikatives Handeln, que compõem essa mesma obra; bem como Treffen Hegels Einwände gegen Kant auch auf die Diskursethik zu? (1986); e Was macht eine Lebensform rational? (1984), reunidos depois em Erläuterungen zur Diskursethik. Frankfurt am Main: Suhrkamp, 1991.

4 Sob esse prisma, os trabalhos mais importantes de Apel, nesse período, são: APEL, K.-O. [1986] Grenzen der Diskursethik? In: Zeitschrift für philosophische Forschung, 1986. v. 40; [1988] Diskurs und Verantwortung: Das Problem des Übergangs zur postkonventionellen Moral. Frankfurt am Main: Suhrkamp, 1988; [1989] Normative Begründung der "kritischen Theorie" durch Rekurs auf lebensweltliche Sittlichkeit? Ein transzendentalpragmatisch orientierter Versuch, mit Habermas gegen Habermas zu denken. In: HONNETH, Axel et al. Zwischenbetrachtungen: im Prozess der Aufklärung. Jürgen Habermas zum 60. Gebursstag. Frankfurt am Main: Suhrkamp; [1990] Diskursethik als Verantwortungsethik. Eine postmetaphysische Transformation der Ethik Kants. In: FORNET-BETANCOURT, R. (Org.). Ethik und Befreiung (Concordia, Reihe Monographien), Aachen, Augustinus-Buchhandlung.

5 Essa posição é apresentada em Erläuterungen zur Diskursethik (1991) e Faktizität und Geltung: Beiträge zur Diskurstheorie des Rechts und des demokratischen Rechstaats (1992), com desdobramentos também em Die Einbeziehung des Anderen (1996) e Wahrheit und Rechtfertigung (1999). 


\section{Referências bibliográficas}

APEL, Karl-Otto. [1973] Transformation der Philosophie Bd. II. Frankfurt am Main: Suhrkamp, 1999.

APEL, Karl-Otto. [1981]. La question d'une fundation ultime de la raison. Critique, tome XXXVII, n. 413, out. 1981.

APEL, Karl-Otto. [1986] Grenzen der Diskursethik? In: Zeitschrift für philosophische Forschung, v. 40, 1986.

APEL, Karl-Otto. [1988] Diskurs und Verantwortung: Das Problem des Übergangs zur postkonventionellen Moral. Frankfurt am Main: Suhrkamp, 1988.

APEL, Karl-Otto. [1989] Normative Begründung der "kritischen Theorie" durch Rekurs auf lebensweltliche Sittlichkeit? Ein transzendentalpragmatisch orientierter Versuch, mit Habermas gegen Habermas zu denken. In: HONNETH, Axel et al. Zwischenbetrachtungen: im Prozess der Aufklärung. Jürgen Habermas zum 60. Gebursstag. Frankfurt am Main: Suhrkamp, 1989.

APEL, Karl-Otto. [1990] Diskursethik als Verantwortungsethik. Eine postmetaphysische Transformation der Ethik Kants. In: FORNETBETANCOURT, R. (Org.). Ethik und Befreiung (Concordia, Reihe Monographien), Aachen, Augustinus-Buchhandlung, 1990.

APEL, Karl-Otto. [1992]. Ética della comunicazione. Milano: Jaca Book, 1992.

APEL, Karl-Otto. [1998]. Auflösung der Diskursethik? Zur Architektonik der Diskurs-differenzierung in Habermas 'Fakzitität und Geltung (Dritter Versuch, mit Habermas gegen Habermas zu denken). In: Auseinandersetzungen. Frankfurt am Main: Suhrkamp, 1998. (S. 727-838).

APEL, Karl-Otto. [2001] La relation entre moral, droit et démocratie: la philosophie de Jürgen Habermas jugée du point de vue d'une pragmatique transcendantale. Les Études Philosophiques, Paris, jan.-mar, n. 1/2001.

HABERMAS, Jürgen. [1963] Teoria y praxis. Madrid: Tecnos, 1987.

HABERMAS, Jürgen. [1967] Arbeit und Interaktion. In: Technik und Wissenschaft als

'Ideologie'. Frankfurt am Main: Suhrkamp, 1968.

HABERMAS, Jürgen. [1968] Erkenntnis und Interesse. 6. Aufl. Frankfurt/Main: Suhrkamp, 1973. 
HABERMAS, Jürgen. [1972] Replik auf Einwände. In: Vorstudien und Ergänzungen zur Theorie des kommunikativen Handelns. Frankfurt am Main: Suhrkamp, 1984.

HABERMAS, Jürgen. [1973] Legitimationsprobleme im Spätkapitalismus. Frankfurt am Main: Suhrkamp, 1973.

HABERMAS, Jürgen. [1981] Theorie des Kommunikativen Handelns. Frankfurt am Main: Suhrkamp Verlag, 1995. (2v.).

HABERMAS, Jürgen. [1983] Diskursethik - Notizen zu einem Begründungsprogramm. In: HABERMAS, J. Moralbewusstsein und Kommunikatives Handeln. Frankfurt am Main: Suhrkamp, 1983.

HABERMAS, Jürgen. [1990] Die nachholende Revolution - Kleine Politische Schriften VII. Frankfurt am Main: Suhrkamp, 1990.

HABERMAS, Jürgen. [1991] Erläuterungen zur Diskursethik. Frankfurt am Main: Suhrkamp, 1991.

HABERMAS, Jürgen. [1992] Faktizität und Geltung: Beiträge zur Diskurstheorie des Rechts und des demokratischen Rechtsstaats. Frankfurt am Main: Suhrkamp, 1998.

HABERMAS, Jürgen. [1996]. Die Einbeziehung des Anderen. Studien zur politischen Theorie. Frankfurt am Main: Suhrkamp, 1996.

HABERMAS, Jürgen. [1999]. Wahrheit und Rechtfertigung - Philosophische Aufsätze.

Frankfurt am Main: Suhrkamp, 1999.

HABERMAS, Jürgen. [2003]. Zur Archiktektonik der Diskursdifferenzierung. Kleine Replik auf eine grosse Auseinandersetzung. In: BÖHLER, D.; KETTNER, M.; SKIRBEKK, G. Reflexion und Verantwortung: Auseinadersetzungen mit Karl-Otto Apel. Frankfurt am Main: Suhrkamp, 2003. 